\title{
Unidades de Landforms na Bacia do Arroio Cadena, Santa Maria - RS
}

Luis Eduardo Robaina

ROBERTO CASSOL

Edgardo Ramos Medeiros

\section{RESUMO}

Este trabalho utiliza a metodologia proposta por LOLLO (1996), para definir na bacia do Arroio Cadena dois sistemas de landforms, baseado no processo geomorfológico, denominados como sistema de dissecação e de acumulação. Estes sistemas foram divididos em porções menores do terreno, que por sua vez, foram caracterizadas em sete unidades homogêneas, descritas em termos de feições morfológicas, tipos de vales, característica do relevo (altitude, amplitude, declividade), drenagem, substrato geológico/ pedológico, uso e ocupação do solo. Tem por objetivo dar uma contribuição para o conhecimento científico e ao planejamento do uso e ocupação do solo na região, por analisar de forma integrada quanto ao meio natural e antrópico, identificando os principais processos geomorfológicos. 


\section{ABSTRACT}

This work uses the methodology proposal by Lollo (1996) to define in the basin of the stream cadena two landforms systems based on the geomorfological process, denominated as dissection and of accumulation areas. These systems were divided in smaller portions of the land, that for its time they are characterized by seven units, described in terms of morphologic features, types of you are worth, characteristic of the relief (altitude, amplitude, declivity), drainage, substratum geologic/pedological, use and occupation of the soil. We has for objective to give a contribution for the scientific knowledge of to how planning the use and occupation of the soil. The analyzing data were integrated with relationship into the natural and anthropic way, identifying the main geomorphological processes.

\section{INTRODUÇÃO}

O município de Santa Maria localiza-se na região central do estado do Rio Grande do Sul, entre as coordenadas geográficas $29^{\circ} 26^{\prime} 52^{\prime \prime}$ e $30^{\circ} 00^{\prime} 19^{\prime \prime}$ de latitude sul e $54^{\circ} 19^{\prime} 33^{\prime \prime}$ e $53^{\circ} 30^{\prime} 44^{\prime \prime}$ de longitude oeste do meridiano de Greenwich, distante aproximadamente a $300 \mathrm{~km}$ da capital, Porto Alegre. Conforme dados do IBGE (2001), sua população ao redor de 250 mil habitantes, dos quais $80 \%$ residem na área urbana (figura 1 ).

Neste trabalho, busca-se através de uma visão integradora a distribuição espacial dos elementos do meio ambiente, enfatizando as pecularidades que são fundamentais para alcançar o entendimento dos processos dinâmicos que ocorrem no sistema com a ativa participação antrópica.

\section{METODOLOGIA}

Conforme Lollo (1996), a sistemática de avaliação de terrenos baseia-se na possibilidade de divisão da área estudada em unidades de terreno. Essa divisão se estabelece a partir do estudo de cartas topográficas de escala 1:10.000, de fotografias aéreas 1:15.000 e de trabalhos de campo, tendo como critério de zoneamento a uniformidade destas parcelas de terreno em termos das feições de relevo, características do substrato e uso e ocupação do solo. 


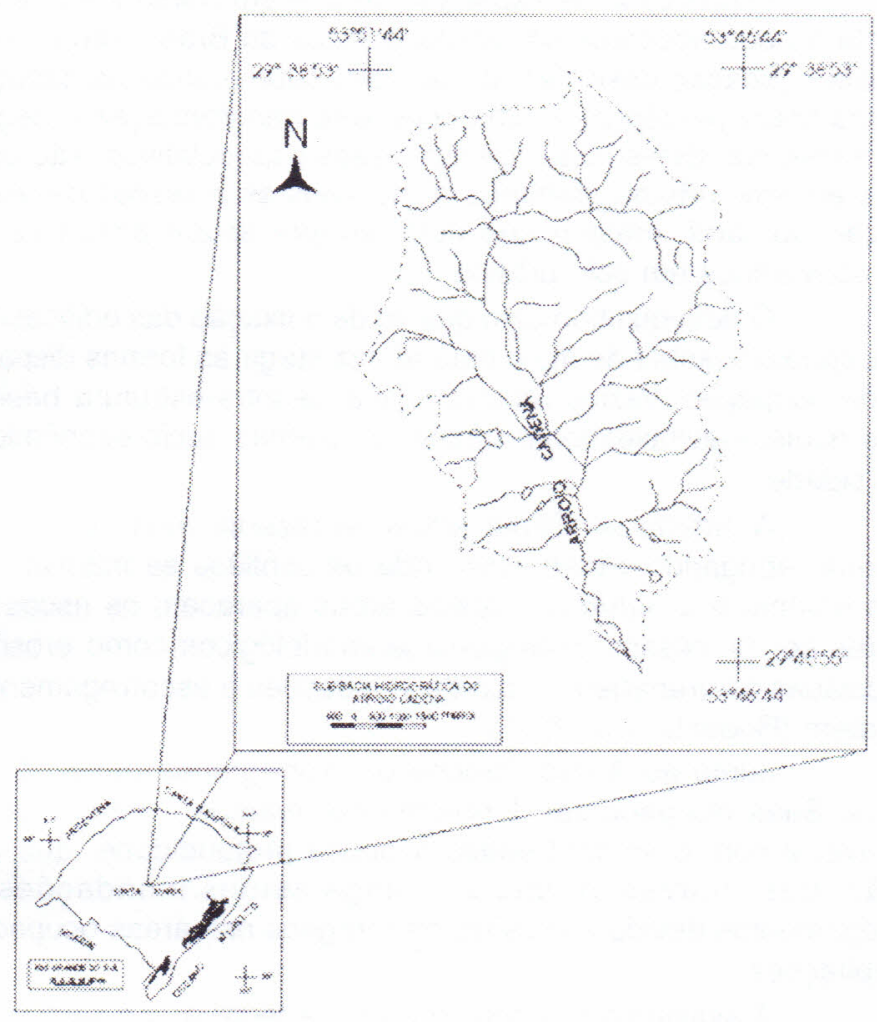

Fig. 1. Mapa de Localização da Bacia do Arroio Cadena

\section{CARACTERÍSTICAS GERAIS}

A Bacia do Arroio Cadena, com aproximadamente $15 \mathrm{~km}$ de extensão drena 6000 ha de área, tem suas principais nascentes no Rebordo do Planalto. O curso principal apresenta na porção inicial uma direção de fluxo E-W, passando logo após para uma direção de fluxo N-S. Contorna os setores norte, noroeste e oeste do sítio urbano da cidade, coincidentemente para onde ocorreu a expansão urbana. Seus afluentes, na sua maioria, se distribuem pela área urbana ocupada pelas edificações, principalmente na margem esquerda. O referido arroio é um afluente da Bacia do Rio Vacacaí, que compõem a Bacia do Guaíba. 
O processo de expansão urbana em Santa Maria é semelhante ao que acontece em várias cidades do Brasil, sendo marcado pela ocupação desordenada do solo, submetendo os espaços livres das áreas periféricas a uma constante transformação e degradação ambiental. Estes locais de interesses especulativos, são convertidos em solo urbano, portanto, disponíveis às pressões de uso e ocupação humana, mesmo que nem sempre sejam passíveis de serem convertidos em solo urbano.

O desequilíbrio com que se dá a fixação das edificações com as condicionantes do meio natural, faz surgir as formas disparatadas de ocupação, vazios urbanos, falta de infra-estrutura básica, etc., as quais, inevitavelmente trazem problemas sócio-econômicos para a cidade.

A cidade de Santa Maria representa muito bem esta conjuntura, abrigando várias vilas onde os conflitos se intensificam entre o homem e a natureza. Nestas áreas aparecem os riscos de acidentes por processos geológicos/geomorfológicos como erosões e, associadas as drenagens, risco de inundações e escorregamentos de margem (Robaina et al.2001).

Junto ao Arroio Cadena ocorrem grande parte destes conflitos. Suas margens são formadas por material inconsolidado, permeável e com o lençol freático à pouca profundidade, que por ocasião das chuvas propiciam alagamentos/inundações e escorregamentos devido a erosões de margens nas áreas ocupadas por habitações.

A avaliação da bacia, a partir da técnica dos landforms, vem sendo utilizada com grande êxito, em diversos trabalhos, como critério de zoneamento do meio físico (Rodrigues, 1998). Tem por objetivo contribuir para o conhecimento científico e ao planejamento do uso e ocupação do solo, na região, por analisar de forma integrada quanto ao meio natural e antrópicos, identificando os principais processos geomorfológicos.

\section{MAPEAMENTO DAS UNIDADES DE LANDFORMS NA BACIA}

$\mathrm{Na}$ aplicação da metodologia proposta por Lollo (1996), na Bacia do Arroio Cadena foram definidas 2 sistemas de landforms, baseados no processo geomorfológico denominados como áreas de dissecação e de acumulação. Estes sistemas foram divididos em porções menores do terreno, que por sua vez, são caracterizados por 7 unidades, descritas em termos de feições geomorfológicas, 
tipos de vales, característica do relevo (altitude, amplitude, declividade), drenagem, substrato geológico/pedológico, uso e ocupação do solo (figura 2 e quadros 1 e 2).

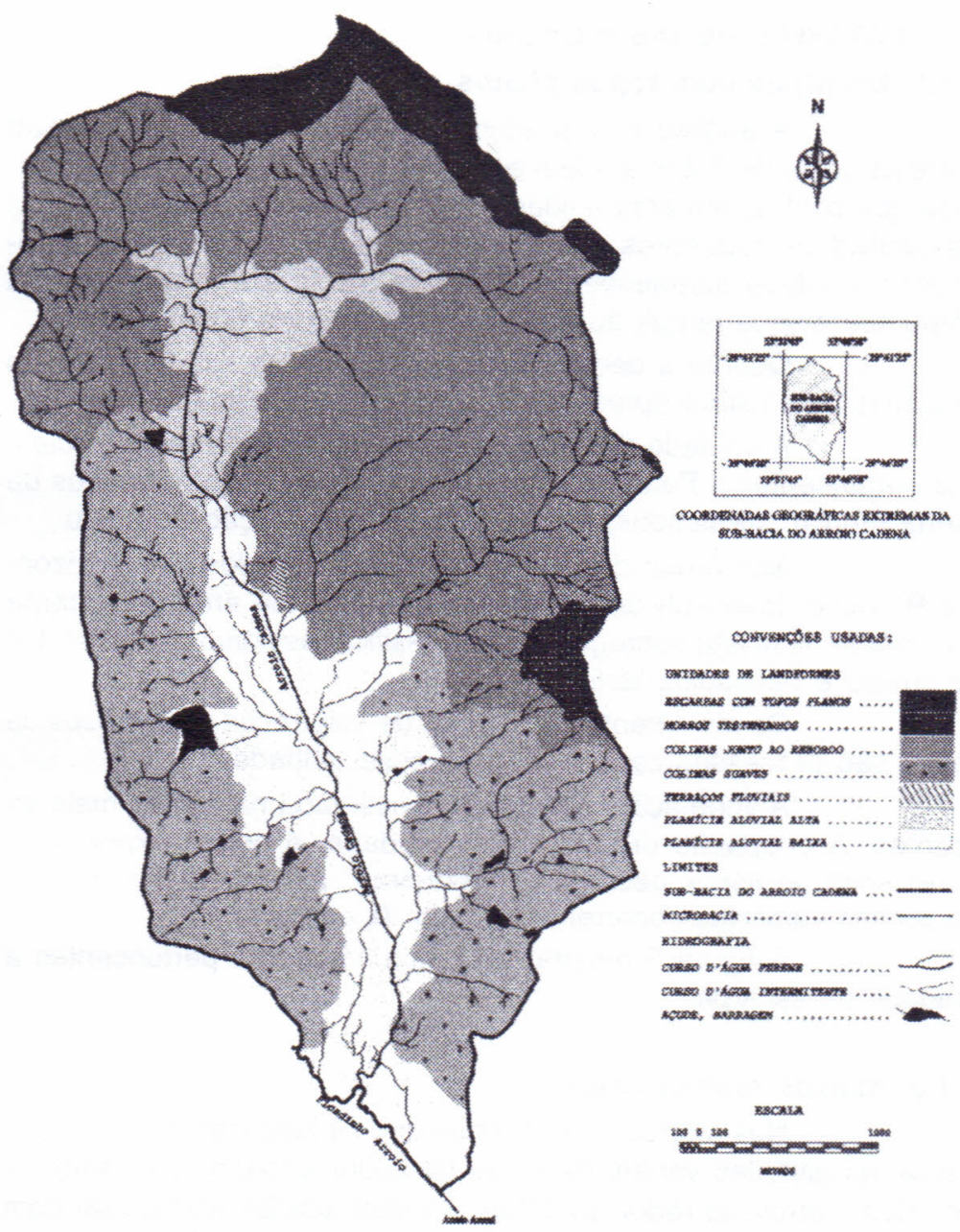

Fig. 2. Mapa das unidades de "Landforms", na sub-bacia hidrográfica do Arroio Cadena, Santa Maria, RS

As unidades do sistema de landforms de dissecação são: escarpas com topos planos, morros testemunhos, colinas junto ao rebordo, colinas suaves. Enquanto que no sistema de landforms 
de acumulação são: terraços fluviais, planície aluvial alta, planície aluvial baixa.

\subsection{SISTEMAS DE DISSECAÇÃO}

\subsubsection{Escarpas com topos planos}

A análise morfométrica identifica altitudes que variam entre as cotas de $300 \mathrm{~m}$ a $438 \mathrm{~m}$ e valores de $160 \mathrm{~m}$ a $250 \mathrm{~m}$ de amplitude que configuram esta unidade. Nessa área são comuns valores de declividade superiores a $47 \%$, sendo que as sub-bacias que compõem a unidade apresentam declividade média acima de $15 \%$. Os comprimentos de rampa apresentam valores entre $600 \mathrm{~m}$ a $900 \mathrm{~m}$.

Quanto a densidade de drenagem as sub-bacias mais próximas da escarpa apresentam valores ao redor de $0,020 \mathrm{~km} / \mathrm{ha}$.

A unidade da escarpa é formada por derrames vulcânicos pertencentes a Formação Serra Geral, associados a arenitos de forma tabular silicificados, representando a Formação Botucatu.

Nas áreas de topo são comuns os solos com horizontes $B$ pouco desenvolvidos. Em geral, os solos na área de escarpa são rasos e com alta pedregosidade, classificados como chernossolos argilúvico e neossolos litólicos.

Os movimentos de massa de solo/rocha e de blocos de rocha são processos característicos dessa unidade.

A vegetação nativa esta preservada nas áreas mais íngremes. A ocupação urbana, nesta unidade, é pouco expressiva, diminuindo os riscos geológicos. Pedreiras para extração de brita de rochas vulcânicas ocorrem ao longo da encosta.

A figura 3 mostra, ao fundo, vertentes pertencentes a unidade de escarpa.

\subsubsection{Morros testemunhos}

Nos morros testemunhos que se localizam a NE e E da Bacia, as altitudes variam de cotas de $200 \mathrm{~m}$ a $270 \mathrm{~m}$, com amplitudes dos morros ao redor de $110 \mathrm{~m}$. As declividades aumentam com as áreas mais elevadas, sendo comuns áreas com valores superiores a $47 \%$. Nesta unidade a declividade média é proxima de $20 \%$, e a extensão das vertentes varia entre $300 \mathrm{~m}$ e $500 \mathrm{~m}$.

As porções superiores dos morros ocorrem capeadas por rochas vulcânicas e arenitos da Formação Botucatu, enquanto, nas porções médias e basais ocorrem rochas sedimentares areníticas e lamíticas das Formações Caturrita e Santa Maria. 


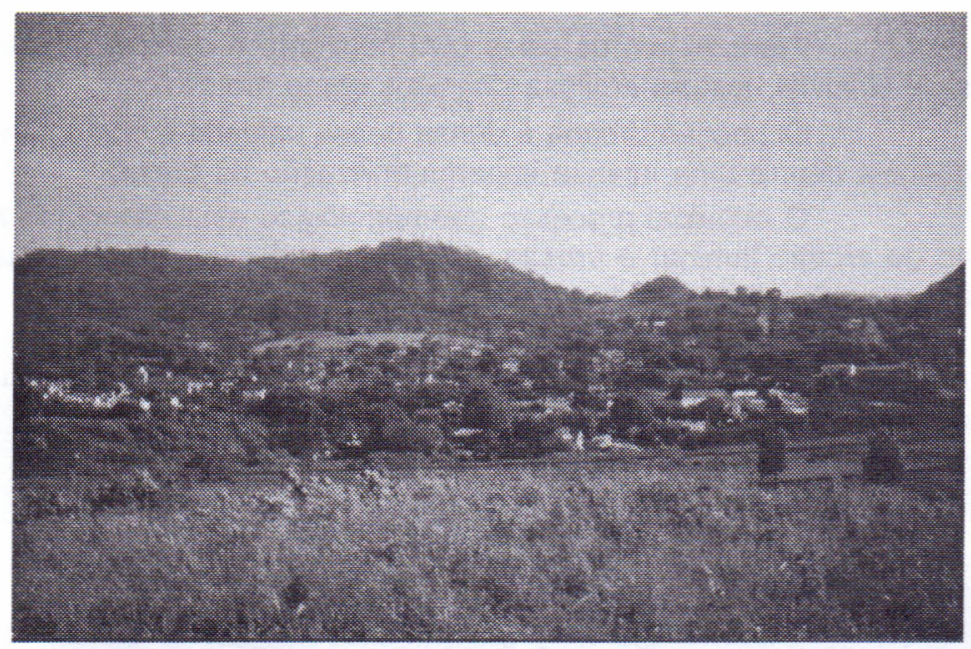

Fig. 3. Vertentes da escarpa

Nas partes de topo ocorrem chernossolos e neossolos litólicos; em direção à base existem argissolos, que se caracterizam por horizonte A silte-areia e horizonte B iluvial, argiloso e com óxidos de ferro.

Erosão e movimentos de massa, em especial de blocos de rocha, são processos que ocorrem junto às vertentes.

baixos.

Devido a ocupação extensiva os riscos geológicos são

\subsubsection{Colinas junto ao rebordo}

O relevo das colinas, mais próximas da encosta, apresentam altitudes entre cotas $142 \mathrm{~m}$ a $155 \mathrm{~m}$. Nessa unidade, as amplitudes das colinas variam entre 36 a $50 \mathrm{~m}$. Os intervalos de declividade estão entre $5-12 \%$, sendo raro valores superiores a $30 \%$. A declividade média fica ao redor de $10 \%$. Comprimentos de rampa entre $700 \mathrm{~m}$ e 1500 m são os característicos.

$\mathrm{Na}$ área de colinas a densidade de drenagem é mais baixa na sub-bacia a NW da área, com 0,013 km/ha; nas sub-bacias com predomínio do substrato lamítico os valores são ao redor de $0,035 \mathrm{~km} / \mathrm{ha}$.

Nas colinas ao norte a seqüência de rochas está representada por arenitos e lamitos e alguns ruditos intraformacionais das Formações Caturrita e Santa Maria. 
Predominam os solos com horizonte A de textura arenosa e B iluvial, textura argilosa definidos como argissolos.

Ocupação urbana é densa nessa unidade e como conseqüência ocorre uma intensa impermeabilização da bacia.

O principal processo geomorfológico está associado a ação da erosão laminar e erosão em sulcos, em especial, junto as cabeceiras das drenagens

Na figura 3 são mostradas em primeiro plano as áreas de ocorrência desta unidade. A figura 4 registra as áreas desta unidade com grande ocupação urbana.

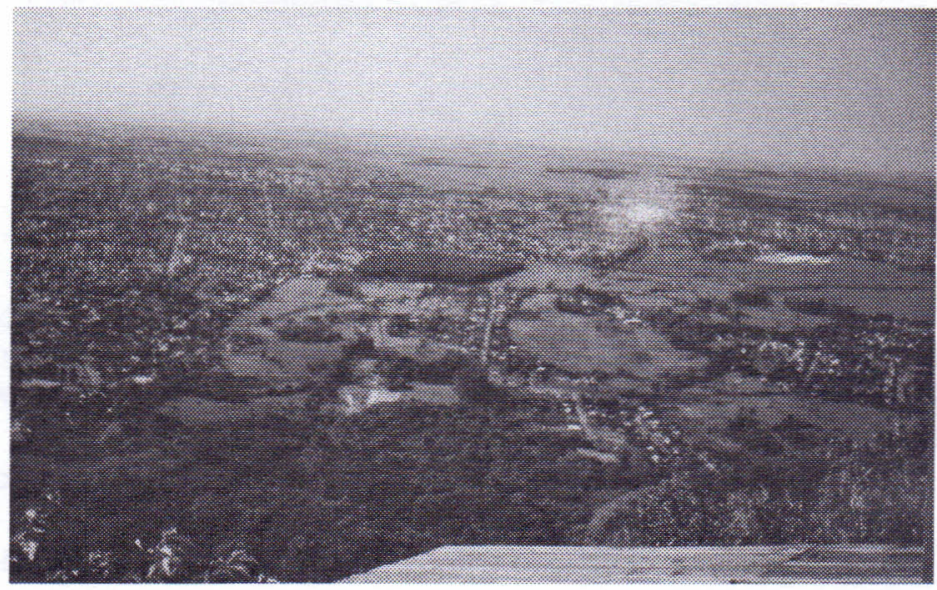

Fig. 4. Colinas ocupadas

\subsubsection{Colinas suaves}

Nesta unidade de relevo, as cotas situa-se entre $100 \mathrm{~m}$ e $134 \mathrm{~m}$. As colinas são relativamente rebaixadas e com valores próximos de $30 \mathrm{~m}$ de amplitude. Representam as áreas do centro-sul da bacia e apresentam declividades predominantes próximas a $5 \%$ e comprimentos de rampa entre $700 \mathrm{~m}$ e $1500 \mathrm{~m}$. Associado ao substrato lamítico, os valores de densidade de drenagem são ao redor de 0,035 $\mathrm{km} / \mathrm{ha}$. Já na sub-bacia mais ao sul, a densidade de drenagem passa para $0,026 \mathrm{~km} / \mathrm{ha}$, provavelmente, devido a ocorrência de um substrato arenítico.

As colinas da porção centro-sul da bacia apresentam o substrato constituído por intercalações de lamitos e arenitos finos, representando as Formações Santa Maria e Rosário do Sul. 
Nesta unidade os solos do tipo argissolos são os predominantes, com horizonte B textural e de coloração vermelha.

A ocupação urbana está associada a algumas vilas populares, mas, predominam áreas de campos e áreas agrícolas.

A erosão é o processo característico, ocorrendo de forma laminar e em sulcos. Os processos erosivos em sulcos podem evoluir para voçorocas.

A figura 5 mostra uma ocupação urbana que inicia nas áreas de colinas suaves.

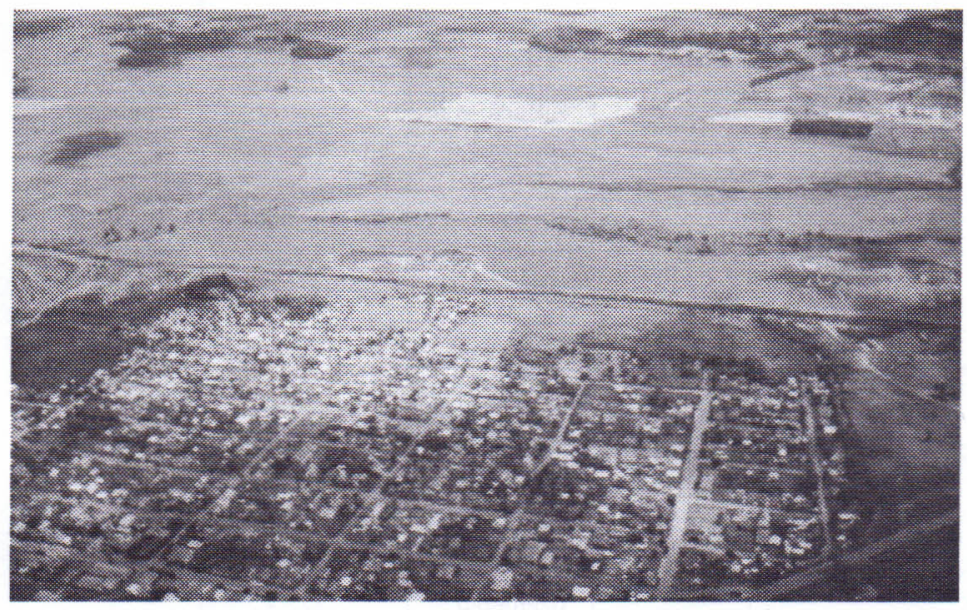

Fig. 5. Colinas suaves e planicie aluvial baixa, junto a vila Urlândia

\subsection{SISTEMAS DE ACUMULAÇÃO}

\subsubsection{Terraços fluviais}

Os terraços são pouco freqüentes e de pouca extensão. Quando definidos encontram-se entre as altitudes de $70 \mathrm{~m}$ a $80 \mathrm{~m}$. Formam bancos com declividades superiores a $12 \%$. Ocorrem isolados refletindo um deslocamento lateral do canal durante o processo de entalhamento.

São constituídos por sedimentos arenosos com seixos de quartzo e intraclastos.

Os solos sobre os terraços estão caracterizados por um horizonte $\mathrm{A}$ bruno avermelhado, franco arenoso, que passa gradualmente para um horizonte B vermelho amarelado, franco argiloso, formando, em geral, os argissolos. 


\begin{tabular}{|c|c|c|c|c|}
\hline $\begin{array}{l}\text { Landforms de } \\
\text { Dissecação }\end{array}$ & $\begin{array}{l}\text { Escarpas com } \\
\text { Topos Planos }\end{array}$ & $\begin{array}{c}\text { Morros } \\
\text { Testemunhos }\end{array}$ & $\begin{array}{c}\text { Colinas Junto ao } \\
\text { Rebordo }\end{array}$ & Colinas Suaves \\
\hline Altitudes (m) & 300 a 438 & 200 a 270 & 142 a 155 & 100 e 134 \\
\hline Amplitudes $(m)$ & 160 a 250 & ao redor de 110 & entre 36 a 50 & próximos de 30 \\
\hline Declividade(\%) & $\begin{array}{l}\text { comuns } \\
\text { superiores a } \\
47, \text { média } \\
\text { acima de } 20\end{array}$ & $\begin{array}{c}\text { aumenta com a } \\
\text { altura; } \\
\text { média próxima } \\
\text { de } 20\end{array}$ & $\begin{array}{l}\text { 5-12 } \\
\text { predominam, } \\
\text { média ao redor } \\
\text { de } 10\end{array}$ & $\begin{array}{l}\text { predominante } \\
\text { próxima a } 5\end{array}$ \\
\hline $\begin{array}{l}\text { Comp. de } \\
\text { Rampa(m) }\end{array}$ & 600 a 900 & 300 e 500 & 700 e 1500 & 700 e 1500 \\
\hline $\begin{array}{c}\text { Densidade de } \\
\text { Drenagem } \mathrm{km} / \mathrm{ha}\end{array}$ & 0,020 & & 0,013 a 0,035 & 0,035 a 0,026 \\
\hline $\begin{array}{l}\text { Substrato } \\
\text { Geológico }\end{array}$ & $\begin{array}{l}\text { vulcânicos, } \\
\text { arenitos de } \\
\text { forma tabular }\end{array}$ & $\begin{array}{l}\text { vulcânicas e } \\
\text { arenitos e } \\
\text { lamitos. }\end{array}$ & $\begin{array}{c}\text { Arenitos, } \\
\text { lamitos e ruditos } \\
\text { intraformacional }\end{array}$ & $\begin{array}{l}\text { intercalações } \\
\text { de lamitos e } \\
\text { arenitos finos, }\end{array}$ \\
\hline $\begin{array}{c}\text { Feições } \\
\text { Pedológicas }\end{array}$ & $\begin{array}{c}\text { rasos e alta } \\
\text { pedregosidade }\end{array}$ & $\begin{array}{c}\text { topo } \\
\text { chernossolos e } \\
\text { neossolos } \\
\text { litólicos; base } \\
\text { argissolos, } \\
\end{array}$ & argissolos & $\begin{array}{l}\text { argissolos são } \\
\text { os } \\
\text { predominantes }\end{array}$ \\
\hline $\begin{array}{l}\text { Uso e Ocupação } \\
\text { do Solo }\end{array}$ & $\begin{array}{c}\text { Vegetação } \\
\text { nativa } \\
\text { preservada, } \\
\text { baixa } \\
\text { ocupação } \\
\text { agrícola }\end{array}$ & $\begin{array}{c}\text { Veg. nativa, } \\
\text { reflorestam. e } \\
\text { campos. baixa } \\
\text { ocupação } \\
\text { urbana }\end{array}$ & $\begin{array}{l}\text { Ocupação urbana } \\
\text { densa }\end{array}$ & $\begin{array}{l}\text { vilas populares, } \\
\text { predomínio de } \\
\text { campos e áreas } \\
\text { agrícolas }\end{array}$ \\
\hline $\begin{array}{l}\text { Processos } \\
\text { Geológicos }\end{array}$ & $\begin{array}{l}\text { queda de } \\
\text { bloco, } \\
\text { escorreg. de } \\
\text { solo/rocha }\end{array}$ & $\begin{array}{c}\text { rolamento e } \\
\text { queda de } \\
\text { blocos, erosão }\end{array}$ & $\begin{array}{l}\text { erosão laminar e } \\
\text { erosão em sulcos }\end{array}$ & $\begin{array}{l}\text { erosão laminar } \\
\text { e em sulcos. }\end{array}$ \\
\hline
\end{tabular}

Quadro 1: Unidades de dissecação

Os terraços formam bancadas bem acima do nível atual do rio, não sendo atingidos pela água, nem mesmo nas enchentes.

A ação da erosão pode ser significativa devido as características dos solos, que são arenosos e com baixa coesão.

\subsubsection{Planície aluvial alta}

Esta unidade está definida pelas altitudes da planície de inundação colocada entre as cotas de $70 \mathrm{~m}$ e $90 \mathrm{~m}$.

A planície de inundação é formada por áreas planas com declividades inferiores a $2 \%$. São áreas mal drenadas com lençol freático próximo a superfície. 
A deposição ocorre durante os períodos de cheias, onde a carga em suspensão é sedimentada pela planície de inundação. Os depósitos apresentam textura predominante de areia fina, com espessura de $3 \mathrm{~m}$ junto a rua Venâncio Aires. A largura das várzeas variam de $400 \mathrm{~m}$ a $900 \mathrm{~m}$.

Os leitos dos canais são compostos por rochas sedimentares com tamanho de grão de argila até areia fina, mais susceptiveis à erosão.

Os solos são hidromórficos com lençol freático próximo a superfície, apresentando problemas com fundações, que devem ser profundas para evitar riscos geotécnicos.

Ocupação urbana está representada por vilas populares, localizadas na margem do arroio. Nestas áreas, além da impermeabilização, ocorre lançamento de esgotos, lixo e águas servidas diretamente no arroio.

Nas áreas onde a vazão é elevada verifica-se o aprofundamento do canal. Além da erosão vertical, ocorre a erosão lateral, que se constitui em um processo de risco nas regiões com ocupações nas margens, devido aos movimentos de massa nas vertentes.

\subsubsection{Planície aluvial baixa}

As altitudes da planície de inundação ocorrem em cotas inferiores a $70 \mathrm{~m}$, ao redor de $65 \mathrm{~m}$. É formada por áreas planas com declividades inferiores a $2 \%$, constituindo em uma deposição que ocorre durante os períodos de cheias, onde a carga em suspensão é depositada pela planície de inundação. Os depósitos de várzea, nessa unidade, apresentam um textura areno-argilosa e a espessura é variada, mas pode chegar a $5 \mathrm{~m}$ na vila Oliveira. A largura das várzeas variam de $1000 \mathrm{~m}$ a $1500 \mathrm{~m}$.

Solos são hidromórficos, permanecendo inundados nos períodos de cheias. Os problemas geotécnicos estão associados ao escoamento e as fundações.

Os canais fluviais cruzam rochas sedimentares lamíticas a areníticas. Nessa unidade ocorrem extração de argila para fabricação de tijolos e cerâmica vermelha.

O uso e ocupação caracteriza-se pela presença de vilas populares (figura 5), áreas de campos com pecuária extensiva e atividades agrícolas.

Os processos estão associados a inundação e erosão 
das margens, além disso, nas áreas onde a descarga diminui ocorre a deposição de sedimentos no leito.

\begin{tabular}{|c|c|c|c|}
\hline $\begin{array}{l}\text { Landforms ce } \\
\text { Acumulação }\end{array}$ & Terraços Fluviais & $\begin{array}{c}\text { Planície Aluvial } \\
\text { Alta }\end{array}$ & Planície Aluvial Baixa \\
\hline Altitudes(m) & 70 a 80 & 70 e 90 & Inferior a cota de 70 \\
\hline Declividades(\%) & superiores a 12 & inferiores a 2 . & inferiores a 2. \\
\hline $\begin{array}{l}\text { Características } \\
\text { Geológicas }\end{array}$ & $\begin{array}{l}\text { arenosos com } \\
\text { seixos de quartzo } \\
\text { e intraclastos }\end{array}$ & $\begin{array}{l}\text { predominante de } \\
\text { areia fina }\end{array}$ & $\begin{array}{c}\text { deposição durante os } \\
\text { periodos de cheias }\end{array}$ \\
\hline $\begin{array}{l}\text { Características } \\
\text { Pedológicas }\end{array}$ & Argissolos. & hidromórficos. & hidromórficos, \\
\hline $\begin{array}{c}\text { Feições } \\
\text { Importantes }\end{array}$ & & $\begin{array}{c}\text { Alta ocupação por } \\
\text { moradias }\end{array}$ & $\begin{array}{l}\text { Ocorrem extração de } \\
\text { barro para fabricação } \\
\text { de tijolos e cerâmica }\end{array}$ \\
\hline $\begin{array}{l}\text { Espessura e } \\
\text { Extensão dos } \\
\text { Depósitos }\end{array}$ & $\begin{array}{c}\text { pouco freqüentes } \\
\text { e de pouca } \\
\text { extensão }\end{array}$ & $\begin{array}{l}\text { Espessura de } 3 \mathrm{~m} . \\
\text { A largura variam } \\
\text { de } 400 \text { a } 900 \mathrm{~m}\end{array}$ & $\begin{array}{c}\text { Espessura } 5 \mathrm{~m} . \mathrm{A} \\
\text { Iargura entre } 1000 \mathrm{~m} \text { a } \\
1500 \mathrm{~m} .\end{array}$ \\
\hline $\begin{array}{l}\text { Uso e Ocupação } \\
\text { do Solo }\end{array}$ & & $\begin{array}{c}\text { vilas populares, } \\
\text { áreas } \\
\text { impermeabilizadas }\end{array}$ & $\begin{array}{c}\text { vilas populares, áreas } \\
\text { de campos e } \\
\text { atividades agrícolas }\end{array}$ \\
\hline $\begin{array}{l}\text { Processos } \\
\text { Geológicos }\end{array}$ & $\begin{array}{c}\text { A ação da erosão } \\
\text { pode ser } \\
\text { significativa }\end{array}$ & $\begin{array}{l}\text { Além da erosão } \\
\text { vertical, ocorre a } \\
\text { erosão lateral } \\
\text { movimentos de } \\
\text { massa. }\end{array}$ & $\begin{array}{l}\text { Erosão nas margens e } \\
\text { deposição de } \\
\text { sedimentos no leito. }\end{array}$ \\
\hline
\end{tabular}

Quadro 2: Unidades de acumulação

\section{CONSIDERAÇÕES FINAIS}

Uma das vantagens da utilização da técnica de avaliação de terrenos é o fato de poder ser usada como uma ferramenta de mapeamento do meio físico, possibilitando avaliação de processos naturais e definindo pesos que realmente reflitam a susceptibilidade de cada área. Além disso, com base nessa visão integradora dos elementos do meio ambiente, podem ser enfatizadas as peculiaridades que são fundamentais para alcançar o entendimento dos processos dinâmicos que ocorrem com a participação antrópica.

Dessa forma a descrição das unidades de terreno que compõem a Bacia do Arroio Cadena permite integrar os processos naturais com a ação antrópica. Essa descrição fornece elementos que podem orientar a política de ocupação da região. 


\section{REFERÊNCIAS BIBLIOGRÁFICAS}

LOLLO, J. A. de, O uso da técnica de avaliaaçãao do terreno no processo de elaboração do mapeamento geoténico: sistematização e aplicação na quadríccula de Campinas. Tese de Doutorado, EESC/USP, 1996, 253p.

RODRIGUES, B.B. \& PEJON, O. J. A importância dos landforms na elaboração das cartas de susceptibilidade aos movimentos de massa na região de àguas de Lindóia/SP. In: $3^{\circ}$ Simpósio Brasileiro de Cartografia Geotécnica, Florianópolis, 1998, CD-ROM.

ROBAINA, L. E., BERGER, M. CRISTO, S.S.V. \& PAULA, P.M. de Análise dos ambientes de risco no município de Santa Maria RS. Ciência e Natura, v.23, UFSM, 2001.in press. 
Luis Eduardo Robaina lesro@ hanoi.base.ufsm.br ROBERTO CASSOL

Edgardo Ramos Medeiros Departamento de Geociências - LAGEOLAM Centro de Ciências Naturais e Exatas Universidade Federal de Santa Maria Santa Maria, RS - Brasil 